\title{
Stroke and diabetic ketoacidosis - some diagnostic and therapeutic considerations
}

This article was published in the following Dove Press journal:

Vascular Health and Risk Management

8 April 2014

Number of times this article has been viewed

\author{
Aleksandar Jovanovic' \\ Radojica $\vee$ Stolic $^{2}$ \\ Dragisa $\bigvee$ Rasic $^{3}$ \\ Snezana R Markovic- \\ Jovanovic ${ }^{4}$ \\ Vladan M Peric ${ }^{3}$ \\ 'Department of Endocrinology, \\ ${ }^{2}$ Department of Nephrology, \\ ${ }^{3}$ Department of Cardiology, \\ ${ }^{4}$ Department of Pediatrics, University \\ of Pristina-Kosovska Mitrovica, \\ Kosovska Mitrovica, Serbia
}

\begin{abstract}
Cerebrovascular insult (CVI) is a known and important risk factor for the development of diabetic ketoacidosis (DKA); still, it seems that the prevalence of DKA among the patients suffering CVI and its influence on stroke outcome might be underestimated. Diabetic ketoacidosis itself has been reported to be a risk factor for the occurrence of stroke in children and youth. A cerebral hypoperfusion in untreated DKA may lead to cerebral injury, arterial ischemic stroke, cerebral venous thrombosis, and hemorrhagic stroke. All these were noted following DKA episodes in children. At least some of these mechanisms may be operative in adults and complicate the course and outcome of CVI. There is a considerable overlap of symptoms, signs, and laboratory findings in the two conditions, making their interpretation difficult, particularly in the elderly and less communicative patients. Serum $\mathrm{pH}$ and bicarbonate, blood gases, and anion gap levels should be routinely measured in all type 1 and type 2 diabetics, regardless of symptomatology, for the early detection of existing or pending ketoacidosis. The capacity for rehydration in patients with stroke is limited, and the treatment of the cerebrovascular disease requires intensive use of osmotic and loop diuretics. Fluid repletion may be difficult, and the precise management algorithms are required. Intravenous insulin is the backbone of treatment, although its effect may be diminished due to delayed fluid replenishment. Therefore, the clinical course of diabetic ketoacidosis in patients with CVI may be prolonged and complicated.
\end{abstract}

Keywords: CVI, type 2 diabetes complications, acid-base disturbances, fluid management

\section{Introduction}

Cerebrovascular incidents (CVI) are significant and well-known risk factors for the development of diabetic ketoacidosis (DKA); still, the literature data on the precise treatment guidelines for diabetic ketoacidosis occurring concomitantly with a stroke are scarce or completely lacking. The prevalence of stroke as a risk factor for DKA ranges from $0 \%$ in some studies ${ }^{1}$ to as much as $7 \% .^{2}$ In the study by Mbugua et al, CVI was identified as a risk factor for diabetic ketoacidosis in none of the 648 hospitalized diabetic patients aged $12-77$ years. ${ }^{1}$ Forty eight of these patients had DKA (the mean age was $37 \pm 18.2$ years for males; $29.9 \pm 14.3$ for females). Obviously, the diagnostic routines differ in the countries where the studies have been conducted. In the underdeveloped and developing countries, the diagnosis is often based on the obvious clinical symptomatology, rather than the more expensive (and often delayed) laboratory and imaging procedures. In these conditions, diagnosis and therapy focus on solving the main problem (like cardiovascular, cerebrovascular, surgical), while the minor or secondary disorders are often put aside. In our previous clinical practice during the 1980s and the 1990s, for example, we encountered a striking number of nondiagnosed Medical Faculty, University of Pristina-Kosovska Mitrovica, Bulevar Arsenija Carnojevica I79/I0, I 1070 New Belgrade, Serbia Tel +38I $6484 \mid 2856$ Email aleksandar.nenad.jovanovic@gmail. com 
DKA patients who were admitted to the Surgical Clinic at the Clinical-Hospital Centre (Pristina, Yugoslavia) for acute abdominal pain and appendectomized before the true diagnosis was determined by the means of laboratory results.

Considering data from a recent study in the USA, most patients with DKA $(80 \%)$ are between $18-65$ years, while only $18 \%$ are under the age of $18 .{ }^{3}$ Serum $\mathrm{pH}$, bicarbonate, anion gap and blood gas concentrations are not readily determined in all patients with type 2 diabetes in the neurological wards, although it is well-known that the stress-induced ketoacidosis may appear in this type of diabetes. Moreover, the clinical characteristics of ketoacidosis may overlap with the stroke-related clinical features. It appears that the prevalence of DKA in patients with stroke and the importance of stroke as the precipitant factor for the occurrence of diabetic ketoacidosis may be underestimated.

\section{Pathophysiological considerations}

Stress hormone actions during the cerebrovascular incidents may precipitate DKA, but the reverse is also true. ${ }^{4,5}$ Diabetic ketoacidosis itself represents a risk factor for stroke, especially in children and adolescents. There is a substantial risk of acute ischemic or hemorrhagic stroke during an acute episode of DKA.

Systemic inflammation, vascular disorders, increased coagulopathy, and risk of hemorrhage are usually present in DKA. Various types of stroke - ischemic, cerebral venous thrombosis, and hemorrhagic stroke - were observed in children with DKA. ${ }^{5}$ Hyperglycemia and acidosis may contribute to oxidative stress and lead to tissue ischemia. ${ }^{6}$ The risk of thrombosis during DKA is elevated due to the disorder of coagulation, platelet activation, reduction of total volume, and velocity of blood flow. ${ }^{7}$ During the initial DKA treatment, when cerebral perfusion is restored, the ischemic-reperfusion lesions might occur., ${ }^{8,9}$

Coagulation disorders during DKA and their treatment have been found not only in children but also in adults. ${ }^{10}$ In addition, pathological serum levels of protein $\mathrm{C}$, protein $\mathrm{S}$, homocysteine, and von Willebrand factor were noticed. ${ }^{4,9}$

All these mechanisms influencing cerebral circulation may be operative in a senior population with CVI. Endothelial lesions, platelet activation, relative hypofibrinolysis, and the activation of the coagulation system were all registered in adult patients with DKA, ${ }^{10}$ even in the absence of clinical signs of thrombosis.

\section{Clinical features}

There is considerable overlap of symptoms, signs, and laboratory findings in stroke and DKA ${ }^{11}$ (Table 1). It can be assumed that interference of symptoms in the two conditions during the clinical examination may be confusing and their interpretation difficult, particularly in the elderly and less communicative patients. Serum $\mathrm{pH}$, bicarbonate, and blood gas levels should be determined at admission in all diabetic patients suffering stroke (including those with previously diagnosed type 2 diabetes) for the timely diagnosis of overt (eg, $\mathrm{pH}<7.25$; serum $\mathrm{pH}<15 \mathrm{mmol} / \mathrm{L}$ ) or mild/compensated diabetic ketoacidosis ( $\mathrm{pH}, 7.25-7.35$; serum bicarbonate 15-22 $\mathrm{mmol} / \mathrm{L}$ with depressed $\mathrm{pCO}_{2}$ levels). Respiratory depression may interfere and further complicate the distinction between the respiratory and metabolic causes of acidosis; the measurement of the anion gap may be helpful on these occasions.

Due to stroke-induced stress, the blood glucose level is high in the majority of diabetic patients. In addition, as indicated earlier, the serum $\mathrm{pH}$, bicarbonate, and anion gap are not determined routinely in all diabetic patients with a stroke. A significant number of cases of ketoacidosis in patients with cerebrovascular stroke might go unnoticed.

In addition, there is a striking absence of literature data on the management of adult DKA patients with stroke. There are serious limitations to the volume resuscitation rate to avoid rapid volume expansion and overload the cardiovascular system; the parallel and intensive use of osmotic solutions (eg, mannitol) and loop diuretics (furosemide, torsemide, and bumetanide) may deepen the existing dehydration level and aggravate ketoacidosis itself.

On the other hand, it seems that bumetanide, an inhibitor of $\mathrm{Na}-\mathrm{K}-2 \mathrm{Cl}$ cotransport, may also have some positive effects in type 1 DKA patients with cerebral edema; ${ }^{12}$ it improves cerebral metabolic indices during untreated DKA and amelioration of the metabolic declines during the initial DKA treatment. The task of future studies is to prove whether the use of bumetanide in place of furosemide would have a positive impact on an outcome of CVI complicated by DKA.

The insulin therapy itself in diabetic ketoacidosis will have little effect if it is not accompanied by an adequate and intensive rehydration. Here, in addition to constraints to rapid rehydration, the existing dehydration may be aggravated by the use of therapeutic agents for the treatment of stroke, which may further complicate the status of the patient.

Concomitant use of rehydration and other osmotic diuretics is applied in practice, but clear therapeutic guidelines and algorithms are lacking (for example, the optimal rehydration rate, the appropriate doses and application rates of osmotic and other diuretics, and the options for monitoring the volume load including the measurement of central venous pressure). 
Table I Symptoms and signs in diabetic ketoacidosis and stroke: overlapping features

\begin{tabular}{|c|c|c|}
\hline DKA & Stroke & Comments \\
\hline Excessive thirst or drinking lots of fluid & Inability to swallow & \\
\hline Frequent urination & Incontinence & $\begin{array}{l}\text { Frequent urination and incontinence may be difficult } \\
\text { to differentiate in a somnolent/comatose patient }\end{array}$ \\
\hline General weakness & $\begin{array}{l}\text { General weakness, a feeling of } \\
\text { weakness in one arm/leg }\end{array}$ & \\
\hline Nausea and vomiting & Nausea and vomiting & \\
\hline Loss of appetite & Loss of appetite & $\begin{array}{l}\text { Loss of appetite in DKA results from the } \\
\text { predominantly catabolic pattern of metabolism, } \\
\text { nausea, and confusion }\end{array}$ \\
\hline $\begin{array}{l}\text { Confusion, somnolence, } \\
\text { stupor, coma }\end{array}$ & Confusion, somnolence, stupor, coma & $\begin{array}{l}\text { Mental status changes can be seen with mild-to- } \\
\text { moderate DKA; more severe deterioration in mental } \\
\text { status is typical with moderate-to-severe DKA }\end{array}$ \\
\hline Headache & Headache & \\
\hline $\begin{array}{l}\text { Shortness of breath; increased rate } \\
\text { of breathing, Kussmaul type }\end{array}$ & $\begin{array}{l}\text { Increased or decreased breathing } \\
\text { frequency; abnormal breathing patterns, } \\
\text { Cheyne-Stokes type }\end{array}$ & $\begin{array}{l}\text { Breathing patterns may be similar and } \\
\text { interchangeably assigned to either of the diseases }\end{array}$ \\
\hline Generally ill appearance & Generally ill appearance & \\
\hline Dry skin & Skin may be dry or moist & $\begin{array}{l}\text { Dehydration may occur in case of not having access } \\
\text { to water or fluids, or intensive use of osmotic } \\
\text { diuretics }\end{array}$ \\
\hline Dry mouth & Often dry mouth & \\
\hline Increased heart rate & Increased heart rate & \\
\hline Low blood pressure & Mainly high blood pressure, sometimes low & \\
\hline $\begin{array}{l}\text { Distinctive fruity odor on the breath, } \\
\text { fruity-scented breath }\end{array}$ & $\begin{array}{l}\text { Different kinds of breath odor } \\
\text { not uncommon }\end{array}$ & $\begin{array}{l}\text { Fruity scented breath may be hardly recognizable } \\
\text { Moreover, the odor appearing after ingestion of } \\
\text { various fruits may imitate the characteristic odor of } \\
\text { DKA }\end{array}$ \\
\hline High blood sugar level & High sugar level in diabetics & Due to the effect of counterregulatory hormones \\
\hline High ketone level in serum and urine & $\begin{array}{l}\text { Moderately high ketone level in urine } \\
\text { in diabetics, alcohol abuse, starvation }\end{array}$ & \\
\hline Low $(<7.3)$ plasma pH & Serum pH usually normal & \\
\hline Low serum $(<15 \mathrm{mmol} / \mathrm{L})$ bicarbonate & Serum pH bicarbonate usually normal & \\
\hline Increased $(>12)$ anion gap & Anion gap usually $>12$ & \\
\hline
\end{tabular}

Abbreviation: DKA, diabetic ketoacidosis.

\section{General treatment guidelines}

Some of the general treatment guidelines can be defined here:

1. It is extremely important that patients with stroke complicated by diabetic ketoacidosis avoid dehydration because DKA, dehydration, and stroke all correlate with the prothrombotic state and may lead to intravascular thromboembolism. Excessive use of osmotic diuretics especially in the period before the diagnosis of DKA is confirmed - can aggravate the prothrombotic state. Since the use of osmotic and loop diuretics is inevitable in patients with stroke, a careful hydration is recommended to avoid these complications.

2. Fluid resuscitation must be conducted carefully and in small aliquots, with continuous monitoring of blood pressure, hematocrit, and plasma sodium. Minimally invasive procedures should have advantages over the placement of central venous catheters because the insertion of the catheter itself may be a risk factor for cerebrovascular thromboembolism. ${ }^{13}$

3. Infused insulin is a major therapeutic tool for DKA management in patients with CVI. Since fluid resuscitation must be limited, it is wise to expect that diabetic ketoacidosis could have a prolonged clinical course, which again bears a substantial risk for the development of new strokes and complications.

4. Potassium levels should be monitored carefully for all cardiovascular patients with DKA. Hyper- or hypokalemia should be corrected immediately, and insulin-induced changes in intracellular potassium levels should be taken into account when assessing serum potassium levels.

5. Bicarbonate therapy is not recommended except in the cases of extreme, life-threatening ketoacidosis. 


\section{Conclusion}

Even though CVI is widely recognized as an important risk factor for diabetic ketoacidosis, the data on the prevalence of DKA among CVI patients and its influence on the stroke outcome are scarce.

Diabetic ketoacidosis itself was reported to be a risk factor for the occurrence of stroke in children and youth. Arterial ischemic stroke, cerebral venous thrombosis, and hemorrhagic stroke were noted following DKA episodes in children. It is clear that lesions of the endothelium, platelet activation, relative hypofibrinolysis, and activation of the coagulation system are present in adults with DKA, and these mechanisms may influence the outcome of adult diabetics suffering CVI.

There is considerable overlap of symptoms, signs, and laboratory findings in stroke and DKA. Therefore, the measurement of serum $\mathrm{pH}$, bicarbonate, blood gases, and anion gap on admission or as soon as possible should be a routine in all diabetic patients suffering stroke, especially because respiratory depression may hinder the interpretation of the results. In DKA patients suffering CVI, it is important to prevent dehydration, because both DKA and stroke correlate with prothrombotic state and a tendency toward the development of intravascular thromboembolism. Unfortunately, the capacity for rehydration in patients with stroke is often limited, and treatment of the disease requires intensive use of osmotic diuretics and loop diuretics. Fluid repletion may be extremely difficult, and the precise management algorithms are required.

Intravenous insulin and the monitoring and correction of electrolyte imbalance are the backbone of treatment, although the effect of insulin may be diminished due to delayed fluid replenishment. Therefore, the clinical course of diabetic ketoacidosis may be prolonged.

\section{Disclosure}

The authors report no conflicts of interest in this work.

\section{References}

1. Mbugua PK, Otieno CF, Kayima JK, Amayo AA, McLigeyo SO. Diabetic ketoacidosis: clinical presentation and precipitating factors at Kenyatta National Hospital, Nairobi. East Afr Med J. 2005;82(12): S191-S196.

2. Husain SS, Javed MR, Ali SA. Diabetic ketoacidosis; the precipitating entities in patients with type 2 diabetes mellitus. Professional Medical Journal. 2011;18(1):80-82.

3. Kitabchi AE, Umpierrez GE, Murphy MB, Kreisberg RA. Hyperglycemic crises in adult patients with diabetes: a consensus statement from the American Diabetes Association. Diabetes Care. 2006;29(12):2739-2748.

4. Burzynski J. DKA and thrombosis. CMAJ. 2005;173(2):132.

5. Mahmud FH, Ramsay DA, Levin SD, Singh RN, Kotylak, T, Fraser DD. Coma with diffuse white matter hemorrhages in juvenile diabetic ketoacidosis. Pediatrics. 2007;120(6):e1540-e1546.

6. Lin JJ, Lin KL, Wang HS, Wong AM, Hsia SH. Occult infarct with acute hemorrhagic stroke in juvenile diabetic ketoacidosis. Brain Dev. 2008;30(1):91-93.

7. Glaser NS, Wootton-Gorges SL, Marcin JP, et al. Mechanism of cerebral edema in children with diabetic ketoacidosis. J Pediatr. 2004;145(2): 164-171.

8. Alvarez-Sabín J, Molina CA, Ribó M. Impact of admission hyperglycemia on stroke outcome after thrombolysis: risk stratification in relation to time to reperfusion. Stroke. 2004;35(11):2493-2498.

9. Edge JA, Hawkins MM, Winter DL, Dunger DB. The risk and outcome of cerebral oedema developing during diabetic ketoacidosis. Arch Dis Child. 2001;85(1):16-22.

10. Scibilia J, Finegold D, Dorman J, Becker D, Drash A. Why do children with diabetes die? Acta Endocrinol Suppl (Copenh). 1986;279: 326-333.

11. Jovanovic A, Stolic R, Peric V, Markovic-Jovanovic S. Distinctive characteristics and specific management of diabetic ketoacidosis in patients with acute myocardial infarction, stroke and renal failure. In: Escher AP, Li A, editors. Type 1 Diabetes. Rijeka, Croatia: IntechOpen; 2013:313-330.

12. Kahle KT, Barnett SM, Sassower KC, Staley KJ. Decreased seizure activity in a human neonate treated with bumetanide, an inhibitor of the $\mathrm{Na}(+)-\mathrm{K}(+)-2 \mathrm{Cl}(-)$ cotransporter NKCC1. J Child Neurol. 2009;24(5): $572-576$.

13. Kusminsky RE. Complications of central venous catheterization. J Am Coll Surg. 2007;204(4):681-696.
Vascular Health and Risk Management

\section{Publish your work in this journal}

Vascular Health and Risk Management is an international, peerreviewed journal of therapeutics and risk management, focusing on concise rapid reporting of clinical studies on the processes involved in the maintenance of vascular health; the monitoring, prevention and treatment of vascular disease and its sequelae; and the involvement of

\section{Dovepress}

metabolic disorders, particularly diabetes. This journal is indexed on PubMed Central and MedLine. The manuscript management system is completely online and includes a very quick and fair peer-review system, which is all easy to use. Visit http://www.dovepress.com/ testimonials.php to read real quotes from published authors. 